Molecules 2008, 13, 931-937

\title{
molecules
}

ISSN 1420-3049

(C) 2008 by MDPI

www.mdpi.org/molecules

Full Paper

\section{New Monoterpenoid Coumarins from Clausena anisum-olens}

\author{
Yun-Song Wang ${ }^{1,2}$, Hong-Pin $\mathrm{He}^{2}$, Jing-Hua Yang ${ }^{1}$, Ying-Tong $\mathrm{Di}^{2}$ and Xiao-Jiang Hao ${ }^{2, *}$
}

1 Key Laboratory of Medicinal Chemistry for Natural Resource, Ministry of Education, School of Chemical Science and Technology, Yunnan University, Kunming 650091, P.R. China; E-mails: wangys@ynu.edu.cn (Yun-Song Wang); yangjh@ynu.edu.cn (Jing-Hua Yang)

2 State Key Laboratory of Phytochemistry and Plant Resources in West China, Kunming Institute of Botany, Chinese Academy of Sciences, Kunming 650204, P. R. China; E-mails: hehongping@mail.kib.ac.cn (Hong-Pin He),diyt@mail.kib.ac.cn (Ying-Tong Di)

* Author to whom correspondence may be addressed; E-mail: haoxj@mail.kib.ac.cn; Tel: +86-871-5223263/ Fax: 86-871-5219684

Received: 19 January 2008; in revised form: 17 April 2008 / Accepted: 17 April 2008 / Published: 19 April 2008

\begin{abstract}
Two new monoterpenoid coumarins: anisucumarin A (1) and B (2), a pair of epimers, were isolated from Clausena anisum-olens. Their structures were established based on extensive spectroscopic analyses.
\end{abstract}

Keywords: Rutaceae; Clausena anisum-olens; anisucumarin A/B; monoterpenoid coumarins

\section{Introduction}

The plants of the Rutaceae family are one of the richest sources of coumarins [1-6]. In this family, plants of Clausena genus are widely distributed in the south of China and many are used in Chinese traditional medicine [7]. Phytochemical studies on Clausena species have mainly focused on coumarins and carbazole alkaloids [4-9]. Some of the isolated coumarins showed interesting biological 
activity, for example, nordentatin displayed strong antibacterial activities [6] and the furanone-coumarin clauslatones A-J exhibited tumor-promotion inhibitory effects [5].

Clausena anisum-olens is a shrub found growing in Hekou County of the Yunnan Province and the leaves and twigs of this plant are used for the treatment of dysentery and arthritis [7]. In a preliminary pharmacological study, the EtOH extract of the leaves and twigs of Clausena anisum-olens exhibited antifungal activities against three Candida species: C. albicans, C. tropicalis, and C. krusei. Previous studies on Clausena anisum-olens resulted in the isolation of a novel cyclopeptide [10]. In the present study, an epimer pair of new monoterpenoid coumarins anisucumarin A (1) and B (2) were isolated. Herein, we report the isolation and structural elucidation of these two new coumarins.

\section{Results and Discussion}

The powdered leaves and twigs of Clausena anisum-olens, collected from Hekou County, Yunnan province, were extracted with $90 \%$ ethanol. The concentrated extract suspended in water was successively extracted with petroleum ether, AcOEt and n-BuOH. The AcOEt extract was subjected to chromatography on silica gel, Sephadex LH-20 and RP C-18 to yield compounds $\mathbf{1}$ and $\mathbf{2}$ as a pair of inseparable epimers.

Figure 1. The key HMBC and ROESY correlations of compounds $\mathbf{1} / \mathbf{2}$.

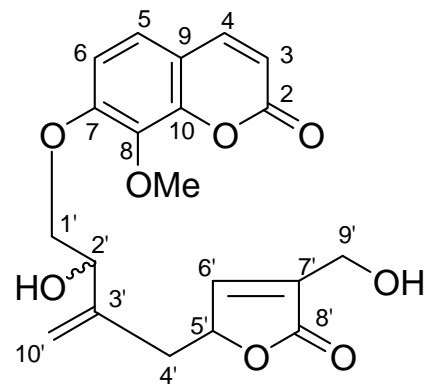

$1 / 2$

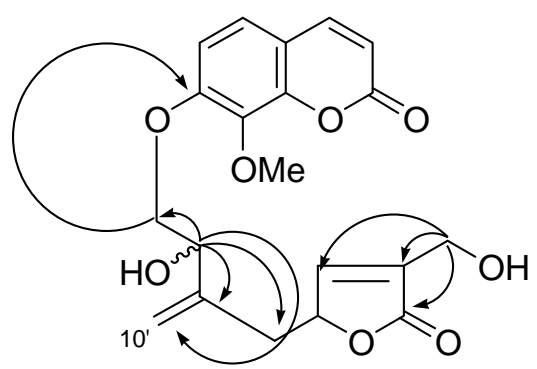

Key HMBC of $\mathbf{1} / \mathbf{2}$

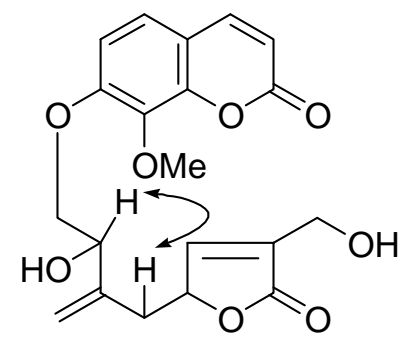

Selected ROESY of major one

Structural elucidation of the new coumarins was mainly determined by spectroscopic 1D- and 2D-NMR experiments $\left({ }^{1} \mathrm{H},{ }^{13} \mathrm{C},{ }^{1} \mathrm{H}-{ }^{1} \mathrm{H}\right.$ COSY, HMQC and HMBC; see Table 1), HR-ESI-MS, UV and IR. The molecular formula of compounds $\mathbf{1} / \mathbf{2}$ was determined to be $\mathrm{C}_{20} \mathrm{H}_{20} \mathrm{O}_{8}$ by HRESI-MS exhibiting the quasimolecular ion at $\mathrm{m} / \mathrm{z} 389.1249[\mathrm{M}+\mathrm{H}]^{+}$, which indicated eleven degrees of unsaturation. The UV spectra of $\mathbf{1} / \mathbf{2}$ displayed typical absorption bands at $\lambda_{\max } 211,256$, and $318 \mathrm{~nm}$, respectively, accompanied with some minor bands. This feature was similar to that of a 7,8-dioxygenated coumarin with a C-10 terpenoid side chain containing a $\gamma$-lactone [5]. The IR bands at 3439 and $1730 \mathrm{~cm}^{-1}$ indicated the presence of hydroxyl groups and $\alpha, \beta$-unsaturated- $\gamma$-lactone group in these molecules. The EI-MS spectra showed fragment ion at $m / z 100$, which was characteristic of 8-OMe coumarin and prominent fragment ion at $\mathrm{m} / \mathrm{z} 370$ corresponding to loss of $\mathrm{H}_{2} \mathrm{O}$ [11].

Through careful analysis of ${ }^{1} \mathrm{H}-\mathrm{NMR}$ spectra the presence of a 7,8-dioxygenated coumarin 
backbone as a common structural unit in $\mathbf{1} / \mathbf{2}$ was further deduced by a methoxy singlet signal at $\delta 3.95$ and two sets of ${ }^{1} \mathrm{H} \mathrm{AB}$ doublets at $\delta_{\mathrm{H}} 6.26$ and 7.86 (each $\mathrm{d}, J=9.6 \mathrm{~Hz}$ ) and $\delta_{\mathrm{H}} 7.31$ and 7.08 (each d, $J$ $=8.7 \mathrm{~Hz}$ ), which were easily assignable to H-3 and H-4 and to H-5 and H-6 on the coumarin skeleton, respectively (Table 1). Analysis of the ${ }^{1} \mathrm{H}$ - and ${ }^{13} \mathrm{C}-\mathrm{NMR}$ spectra, including COSY, HMQC and $\mathrm{HMBC}$, suggested the presence of a $\mathrm{C}_{10}$ terpenoid side chain in $\mathbf{1} / \mathbf{2}$. Two olefinic protons on a terminal methylene at $\delta 5.24,5.42$ (each $\mathrm{d}, J=6.3 \mathrm{~Hz}$ ) were attributed to $\mathrm{H}-10^{\prime}$ according to signal complexity and chemical shift. The other olefinic proton at $\delta 7.55(1 \mathrm{H}, \mathrm{d}, J=1.7 \mathrm{~Hz})$ and a lone $2 \mathrm{H}$-broad singlet at $\delta 4.31$ were observed in the ${ }^{1} \mathrm{H}$ spectrum, and the long-distance correlations between a $2 \mathrm{H}$-broad singlet at $\delta 4.31$ and $\delta 57.0\left(\mathrm{t}, \mathrm{C}-9^{\prime}\right), 137.3\left(\mathrm{~s}, \mathrm{C}-7^{\prime}\right), 151.7\left(\mathrm{~d}, \mathrm{C}-6^{\prime}\right), 174.3\left(\mathrm{~s}, \mathrm{C}-8^{\prime}\right)$ indicated the presence of a 3-hydroxymethyl-3,4-unsaturated- $\gamma$-lactone moiety in the molecules. Two nonequivalent $O$-benzylic protons at $\delta 4.16,4.21$ (each $1 \mathrm{H}, \mathrm{m}$ ) were assigned to $\mathrm{C}-1^{\prime}$ according to $\mathrm{HMBC}$ correlations. In the monoterpenoid side chain, the proton at $\delta 4.59(\mathrm{~m})$ correlated with a methine carbon at $\delta 73.7$ (d) in an HMQC experiment. The observation of HMBC cross peaks between this proton and four carbons at $\delta_{C} 37.1(\mathrm{t}), 73.4(\mathrm{t}), 116.2(\mathrm{t})$ and $144.9(\mathrm{~s})$ suggested that a hydroxyl group was attached to C-2' (Figure 1).

The difference between 1 and 2 was due to the stereochemistry of hydroxyl group at C-2'. The NMR peaks of C-1', C-2', C-3' and C-10' appeared as pairs (Table 1), indicating the presence of $\mathbf{1}$ and its $\mathrm{C}-2^{\prime}$ stereoisomer 2 . The ${ }^{1} \mathrm{H}$ - and ${ }^{13} \mathrm{C}-\mathrm{NMR}$ spectra established that $\mathbf{1}$ and $\mathbf{2}$ consisted of two epimers in a 3:2 ratio. The compound pair resulted in a single spot by multiple solvent systems HPLC. Attempts in the separation of the epimers by HPLC, however, failed to split the products. A reason for this might be a small difference in the interactions between a pair of epimers and the column material for achieving their separation. An analysis of ROESY experiments showed significant NOE correlations between $\mathrm{H}-2^{\prime}$ and $\mathrm{H}-4 \mathrm{~b}^{\prime}$ in the major epimers (Figure 1). However, the same NOE correlation was not observed in the minor epimers. The evidences support the presence of a pair of epimers $\mathbf{1} / \mathbf{2}$ instead of different conformations of one compound.

The configuration of these $O$-terpenoidal coumarins 1 and $\mathbf{2}$ remained to be determined. So far, the stereochemistry of this type of $O$-terpenoidal coumarins reported previously has not been resolved [5, 12-14]. Further structure elucidation on the stereochemistry pertaining to the $\mathrm{C}-2^{\prime}$ and $\mathrm{C}-5^{\prime}$ of $\mathbf{1} / \mathbf{2}$ is in progress. In summary, the ${ }^{1} \mathrm{H}-\mathrm{NMR}$ and ${ }^{13} \mathrm{C}-\mathrm{NMR}$ spectra (Table 1), HMQC, HMBC data established the structures of $\mathbf{1}$ and $\mathbf{2}$ as a pair of epimers of monoterpenoid coumarins (Figure 1).

In a preliminary study, the EtOH extract of Clausena anisum-olens and the two isolated compounds were screened for antifungal activity against $C$. albicans, $C$. tropicalis and $C$. krusei, using the broth microdilution method described in [15]. To validate the MIC end points for antifungal testing of plant extracts, a classification of MIC values used is as follows: strong inhibitors - MIC up to 0.5 $\mathrm{mg} / \mathrm{mL}$; moderate inhibitors - MIC between 0.6 and $1.5 \mathrm{mg} / \mathrm{mL}$ and weak inhibitors - MIC above 1.6 $\mathrm{mg} / \mathrm{mL}$ [16]. The EtOH extract of $C$. anisum-olens exhibited in vitro antifungal activities against $C$. albicans, C. tropicalis and C. krusei, with MIC values of 1.0, 0.25, $0.5 \mathrm{mg} / \mathrm{mL}$. However, the new compound pair 1 and 2 didn't show antifungal activities in vitro in this bioassay. The fractionation of Clausena anisum-olens EtOH extract guided by the bioassays may lead to the isolation of the inhibitor compounds. 
Table 1. The ${ }^{1} \mathrm{H}$ - and ${ }^{13} \mathrm{C}-\mathrm{NMR}$ data for compounds 1 and 2 (in $\mathrm{CD}_{3} \mathrm{OD}, \delta$ in ppm, $J$ in $\mathrm{Hz}$ ).

\begin{tabular}{|c|c|c|c|c|}
\hline \multirow[t]{2}{*}{ No. } & \multicolumn{2}{|c|}{1 (major epimer) } & \multicolumn{2}{|c|}{2 (minor epimer) } \\
\hline & $\delta_{\mathrm{H}}$ & $\delta_{\mathrm{C}}$ & $\delta_{\mathrm{H}}$ & $\delta_{\mathrm{C}}$ \\
\hline 2 & I & $162.7(\mathrm{~s})$ & l & $162.7(\mathrm{~s})$ \\
\hline 3 & $6.26(\mathrm{~d}, 9.5 \mathrm{~Hz})$ & 113.8 (d) & $6.26(\mathrm{~d}, 9.5 \mathrm{~Hz})$ & 113.8 (d) \\
\hline 4 & $7.86(\mathrm{~d}, 9.5 \mathrm{~Hz})$ & $146.0(d)$ & $7.86(\mathrm{~d}, 9.5 \mathrm{~Hz})$ & 146.0 (d) \\
\hline 5 & $7.31(\mathrm{~d}, 8.7 \mathrm{~Hz})$ & $124.7(d)$ & $7.31(\mathrm{~d}, 8.7 \mathrm{~Hz})$ & 124.7 (d) \\
\hline 6 & $7.08(\mathrm{~d}, 8.7 \mathrm{~Hz})$ & $111.5(\mathrm{~d})$ & $7.08(\mathrm{~d}, 8.7 \mathrm{~Hz})$ & 111.5 (d) \\
\hline 7 & 1 & $156.3(\mathrm{~s})$ & l & $156.3(\mathrm{~s})$ \\
\hline 8 & I & $137.3(\mathrm{~s})$ & / & $135.2(\mathrm{~s})$ \\
\hline 9 & I & $115.3(\mathrm{~s})$ & / & $115.3(\mathrm{~s})$ \\
\hline 10 & I & $149.1(\mathrm{~s})$ & / & $145.2(\mathrm{~s})$ \\
\hline l'a & $4.21(\mathrm{~m})$ & $73.4(\mathrm{t})$ & $4.22(\mathrm{~m})$ & $73.4(\mathrm{t})$ \\
\hline $1 ' b$ & $4.16(\mathrm{~m})$ & $73.4(\mathrm{t})$ & $4.15(\mathrm{~m})$ & $73.4(\mathrm{t})$ \\
\hline $2^{\prime}$ & $4.59(\mathrm{~m})$ & 73.7 (d) & $4.57(\mathrm{~m})$ & $73.6(d)$ \\
\hline $3^{\prime}$ & l & $144.9(\mathrm{~s})$ & l & $145.2(\mathrm{~s})$ \\
\hline $4^{\prime} \mathrm{a}$ & $2.64(\mathrm{dd}, 14.2,7.2 \mathrm{~Hz})$ & $37.1(\mathrm{t})$ & $2.71(\mathrm{dd}, 14.6,5.1 \mathrm{~Hz})$ & $37.1(\mathrm{t})$ \\
\hline $4^{\prime} b$ & $2.53(\mathrm{dd}, 14.2,6.3 \mathrm{~Hz})$ & $37.1(\mathrm{t})$ & $2.62(\mathrm{dd}, 14.6,8.1 \mathrm{~Hz})$ & $37.1(t)$ \\
\hline $5^{\prime}$ & $5.38(\mathrm{~m})$ & $82.4(d)$ & $5.34(\mathrm{~m})$ & $82.8(\mathrm{~d})$ \\
\hline $6^{\prime}$ & $7.55(\mathrm{~d}, 1.7 \mathrm{~Hz})$ & $151.7(d)$ & $7.55(\mathrm{~d}, 1.7 \mathrm{~Hz})$ & 151.5 (d) \\
\hline $7^{\prime}$ & / & $137.3(\mathrm{~s})$ & / & $137.3(\mathrm{~s})$ \\
\hline $8^{\prime}$ & / & $174.3(\mathrm{~s})$ & / & $174.3(\mathrm{~s})$ \\
\hline $9^{\prime}$ & $4.31(\mathrm{~s})$ & $57.0(\mathrm{t})$ & $4.31(\mathrm{~s})$ & $57.0(\mathrm{t})$ \\
\hline $10^{\prime} \mathrm{a}$ & $5.42(\mathrm{~d}, 6.3 \mathrm{~Hz})$ & $116.2(\mathrm{t})$ & $5.42(\mathrm{~d}, 6.3 \mathrm{~Hz})$ & $115.9(t)$ \\
\hline $10^{\prime} \mathrm{b}$ & $5.24(\mathrm{~d}, 6.3 \mathrm{~Hz})$ & $116.2(\mathrm{t})$ & $5.24(\mathrm{~d}, 6.3 \mathrm{~Hz})$ & $115.9(t)$ \\
\hline $\mathrm{OMe}$ & $3.95(\mathrm{~s})$ & $61.9(q)$ & $3.95(\mathrm{~s})$ & $61.9(q)$ \\
\hline
\end{tabular}

${ }^{1} \mathrm{H}$ - and ${ }^{13} \mathrm{C}-\mathrm{NMR}$ spectra were obtained at 500 and $125 \mathrm{MHz}$, respectively, and assigned by the ${ }^{1} \mathrm{H}-{ }^{1} \mathrm{H}$ COSY, HMQC and HMBC experiments.

\section{Conclusions}

Two new monoterpenoid coumarins anisucumarin A (1) and B (2), whose separation was not successfully achieved were isolated as a pair of epimers from Clausena anisum-olens. Their structures were established based on extensive spectroscopic studies. The EtOH extract of Clausena anisum-olens and the monoterpenoid coumarins anisucumarin A (1) and B (2) were screened for antifungal activity against C. albicans, C. tropicalis and C. krusei. The EtOH extract of Clausena anisum-olens exhibited in vitro antifungal activities against above bioassays but the monoterpenoid coumarins anisucumarin A (1) and B (2) failed to show detectable inhibitory activity against the fungus. 


\section{Experimental}

\section{General}

Commercial silica-gel plates (Qing Dao Marine Chemical Group Co.) were used for TLC analyses. Melting points was measured on XRC-1 micro-melting point apparatus and uncorrected. UV/VIS Spectra was measured on Shimadzu UV-2401PC spectrophotometer; $\lambda_{\max }$ in $\mathrm{nm}$. IR spectra were obtained on Bio-Rad FTS-135 infrared spectrophotometer, $v_{\max }$ in $\mathrm{cm}^{-1} .{ }^{1} \mathrm{H}$ - and ${ }^{13} \mathrm{C}$ - NMR as well as 2D-NMR spectra were recorded on Brucker DRX-500 spectrometer with TMS as internal standard, coupling constant $J$ in Hz. MS spectra was performed on VG Autospec-3000 mass spectrometers.

\section{Plant material}

The leaves and twigs of Clausena anisum-olens were collected in Hekou County of Yunnan province, P. R. China, in May 2003 and identified by Professor De-Ding Tao of Kunming Institute of Botany. A voucher specimen (No. 02041705) is deposited in State Key Laboratory of Phytochemistry and Plant Resources in West China, Kunming Institute of Botany, Chinese Academy of Sciences.

\section{Extraction and isolation}

The powdered leaves and twigs of Clausena anisum-olens $(22.5 \mathrm{~kg})$ was repeatedly extracted with $\mathrm{EtOH}$ at room temperature. The extract was then concentrated under reduced pressure to give brown syrup, which was partitioned in $\mathrm{H}_{2} \mathrm{O}$ and extracted with solvents into petroleum ether-fraction, AcOEt-fraction and $\mathrm{n}-\mathrm{BuOH}$-fraction fractions. The AcOEt extracts $(110.5 \mathrm{~g})$ were subjected to silica gel column chromatography eluting with PE-AcOEt (4:1, 2:1, 1:1, 2:3), AcOEt, AcOEt-MeOH (8:2, 7:3, 6:4, 1:1), MeOH, by which nine fractions (I-IX) were obtained. Fraction III was resubmitted to silica gel column chromatography, Pharmadex LH-20 (MeOH) and RP C-18 to yield compounds 1/ 2 (11 mg).

Anisucumarin A and B (1 and 2, a pair of epimers ). Light yellow oil; IR (KBr): 3439, 2927, 2855, 1730, 1608; UV $\lambda_{\max }(\mathrm{MeOH}) \mathrm{nm}$ : $318,256,211 ;{ }^{1} \mathrm{H}-\mathrm{NMR}\left(\delta \mathrm{ppm}, \mathrm{CD}_{3} \mathrm{OD}\right)$ and ${ }^{13} \mathrm{C}-\mathrm{NMR}$ : see Table 1; EI-MS m/z 388 ([M] $\left.]^{+}, 100\right), 370$ (15), 358 (5), 339 (4), 205 (26), 192 (100), 164 (22); HR-ESI-MS $\mathrm{m} / \mathrm{z} 389.1249\left([\mathrm{M}+1]^{+}\right)\left(\right.$calcd for $\left.\mathrm{C}_{20} \mathrm{H}_{20} \mathrm{O}_{8} 389.1236\right)$.

\section{Assay for biological activity}

The broth microdilution test M27-A2 [15] was used for the assessment of in vitro antifungal activity of the EtOH extract of Clausena anisum-olens and the compounds against Candida albicans ATCC 90028, Candida tropicalis ATCC 750, Candida krusei ATCC 6258. Amphotericin B was used as a reference drug. The procedure was performed in RPMI 1640 medium buffered to $\mathrm{pH} 7.0$ with 3-morpholinopropane-1-sulfonic acid $(0.165 \mathrm{~mol})$. Drug-free controls were included. The minimal inhibitory concentrations (MICs) were determined after $24 \mathrm{~h}$ and $48 \mathrm{~h}$ of static incubation at $35^{\circ} \mathrm{C}$. 


\section{Acknowledgements}

This work was supported by Science Foundation of Yunnan University (Grant No. 2004Q004A and 2005Z001A) and Science Foundation of Yunnan (Grant No. 2006B0003Q).

\section{References}

1. Phuwapraisirisan, P.; Surapinit, S.; Sombund, S.; Siripong, P.; Tip-pyang, S. Feroniellins A-C, novel cytotoxic furanocoumarins with highly oxygenated $\mathrm{C}_{10}$ moieties from Feroniella lucida. Tetrahedron Lett. 2006, 47, 3685-3688.

2. Chlouchi, A.; Muyard, F.; Girard, C.; Waterman, P. G.; Bévalot, F. Coumarins from the twigs of Diplolaena mollis P. G. Wilson (Rutaceae). Biochem. Syst. Ecol. 2005, 33, 967-969.

3. Nájera, C.; Yus, M. Natural products with polyene amide structures. Stud. Nat. Prod. Chem. 2000, 21, 373-455.

4. He, H. P.; Shen, Y. M.; He, Y. N.; Yang, X. S.; Zhu, W. M.; Hao, X. J. Six New O -Terpenoidal Coumarins, Excavacoumarins B-G from Clausena excavata. Heterocycles 2000, 53, 2067-2070.

5. Ito, C.; Itoigawa, M.; Katsuno, S.; Omura, M.; Tokuda, H.; Nishino, H.; Furukawa, H. Chemical Constituents of Clausena excavata: Isolation and Structure Elucidation of Novel Furanone-Coumarins with Inhibitory Effects for Tumor-Promotion. J. Nat. Prod. 2000, 63, 1218-1224.

6. Huang, S. C.; Wu, P. L.; Wu, T. S. Two coumarins from the root bark of Clausena excavata. Phytochemistry 1997, 44, 179-181.

7. Institutum Botanicum Kunmingenge Academiae Sinicae. Flora Yunnanica (Spermatophyta); Wu, C.Y., Ed.; Science Press: Beijing, 2001; Tomus 6, p. 767 (in Chinese).

8. Chakraborty, A.; Chowdhury, B. K.; Bhattacharyya, P. Clusenol and clausenine-two carbazole alkaloids from Clausens anisata. Phytochemistry 1995, 40, 295-298.

9. Wu, T. S.; Huang, S. C.; Wu, P. L. Carbazole-pyranocoumarin dimer and binary carbazole alkaloid from Clausena excavata. Tetrahedron Lett. 1996, 37, 7819-7822.

10. Wang, Y. S.; He, H. P.; Yang, J. H.; Shen, Y. M.; Zhou, J.; HAO, X. J. A New Cyclopeptide from Clausena anisum-olens. Helv. Chim. Acta 2005, 88, 2345 -2348.

11. Takemura, N. K.Y.; Hirusawa, T.; Motoharu, J. I.; C.; Ito, Furukawa, H. Four New Furanone-Coumarins from Clausena excavata. Chem. Pharm. Bull. 2000, 48, 582-584.

12. Wu, T. S.; Huang, S. C.; Wu, P. L. Pyrano and furocarbazole alkaloids from the root bark of Clausena excavata. Heterocycles 1997, 45, 969-973.

13. Nakamura, K.; Takemura, Y.; Ju-ichi, M.; Ito, C.; Furukawa, H. Three New Coumarins from Clausena excavata. Heterocycles 1998, 48, 549-553.

14. Thuy, T. T.; Ripperger, H.; Porzel, A.; Sung, T. V.; Adam, G. Counlarins, limonoids and an alkaloid from Clausena excavata.. Phytochemistry 1999, 52, 511-516.

15. National Committee for Clinical Laboratory Standards. Reference Method for Broth Dilution Antifungal Susceptibility Testing of Yeast, Approved Standard-Second Edition M27-A2. National Committee for Clinical Laboratory Standards: Wayne, PA, USA; 2002. 
16. Aligiannis, N.; Kalpotzakis, E.; Mitaku, S.; Chinou, I.B. Composition and antimicrobial activity of the essential oils of two Origanum species. J. Agric. Food Chem. 2001, 40, 4168 -4170.

Sample Availability: Available from the authors.

(C) 2008 by MDPI (http://www.mdpi.org). Reproduction is permitted for noncommercial purposes. 